\title{
Fabrication and Characterisation of Bronze Pads and Comparison with Commercial Bronze Pads
}

\author{
A. DemiR* \\ Faculty of Technology, Department of Metallurgical and Materials Engineering, Sakarya University, \\ Serdivan, Sakarya, Turkey
}

\begin{abstract}
CuSn10 pre-alloyed bronze with iron and graphite powders were mixed, pressed and sintered for the bronze pad fabrication. The powder mix was pressed under pressure in the range of 100-600 MPa and sintered at temperatures between $780-850^{\circ} \mathrm{C}$. The optimum compression was at $500 \mathrm{MPa}$ and the optimal sintering temperatures was $730{ }^{\circ} \mathrm{C}$. 2 wt.\% of graphite addition was sufficient to adjust the friction and wear properties of produced bronze pad samples. Optical microscope and SEM images showed that a homogenous powder mix was achieved. The produced bronze samples and the commercial ones were compared and beneficial properties of them were determined. The wear behaviours of both the produced friction materials and the commercial pads were examined. The coefficient of friction and wear rates were determined. The sintered bronze samples and the commercial bronze pads have exhibited similar wear behaviour, although the commercial one have contained ceramic particles.
\end{abstract}

DOI: 10.12693/APhysPolA.129.880

PACS/topics: 81.20.Ev

\section{Introduction}

Copper and copper alloys have been widely used in many industrial fields, such as automobile, marine and machinery because of their excellent ductility, thermal conductivity, good electrical conductivity and corrosion resistance [1]. The leaded-bronzes have been extensively used as bearings in industry because of their excellent tribological properties. However, they also show some distinct shortcomings, such as low tensile and creep strength as well as low hardness, resulting in the failure of mechanical parts [2].

In the past, several different types of materials such as copper alloys, like leaded bronzes, aluminium bronzes, and phosphorus bronzes have been studied for their tribological properties [3]. These materials were tested in both dry and in lubricated conditions against a steel counterpart, which is used as the shaft material in most applications. Lubricants are normally used to reduce friction and minimize wear in case of sliding contacts. Sliding bearings produced by powder metallurgical processes are generally employed in mechanical engineering, in the car industry, and the production of electric motors, optical instruments and precision mechanics [4]. Advance in powder metallurgy technology offers various types of self-lubricating bearings, such as solid lubricant embedded bearings, oil-impregnated bronze, iron, iron graphite bearing and so on [5]. For such materials the focus has been mostly on the applications in ambient dry sliding and at high temperature. Graphite acts as a solid lubricant when it is structurally free and is included in lubricating separating films over the friction surface.

\footnotetext{
*e-mail: ademir@sakarya.edu.tr
}

However, graphite must adhere to the composite matrix to obtain a strong conglomerate produced by sintering of a pressed mixture of starting powders in a protective environment [6].

In this study, sintered $\mathrm{Cu}$-based frictional materials were developed by using powder metallurgy (PM) method. The materials are aimed for application in an automotive industry as a dry friction clutches. Effects of sintering temperature and composition on mechanical and tribological properties were determined. Wear properties of the friction materials were developed for the clutch application and compared with a commercial bronze pad, which was intended for the heavy duty vehicles.

\section{Experimental procedure}

CuSn10 bronze powder with mean grain size of $150 \mu \mathrm{m}$ was supplied from Gürel Makine-Turkey. It was mixed with $10 \%$ of iron powder with average size of $100 \mu \mathrm{m}$. Graphite with mean particle size of $23 \mu \mathrm{m}$ was added in increasing amounts to bronze powders to achieve the value of coefficient of friction of clutch linings. Graphite was added to CuSn10 tin bronze powder in increments of $2 \mathrm{wt} . \%$ up to $8 \mathrm{wt} . \%$, to examine the effect of graphite content on the wear properties of powdermetallurgical (PM) bronze pads. All powders were homogeneously mixed and uniaxially pressed in the range of pressures of 100-600 MPa. Forming pressure of $500 \mathrm{MPa}$ was selected for the following sample preparation since this pressure was ideal for the PM bronze applications. The green bodies then were sintered under argon atmosphere at temperatures between $780-850^{\circ} \mathrm{C}$ for 1 hour. An atmosphere-controlled $\mathrm{SiC}$ resistance alumina tube furnace was used for sintering studies. After consolidation, pin-on disk wear tests were carried out for sintered bronze samples. The wear tests were performed under 
different loads and different velocities. SEM and EDS analysis were accomplished either for home-made bronze pads or commercial bronze pads to compare structure and compositions.

\section{Results and discussion}

The sintered bronze pad samples were polished and image analysis was carried out. Optical microscope and SEM images of the produced samples are given in Figs. 1a and $1 \mathrm{~b}$, respectively. The graphite powder was accumulated in the grain boundaries. This graphite plays important role during friction and acts as solid lubrication which drops coefficient of friction. In the SEM image of sintered bronze, the grain boundaries are much more apparent and the porosity is visible. During wear tests, these porosity and intergranular graphite restrain shining of the bronze sample surfaces and prevent noisy friction. This is quite important for the friction materials so that the clutch lining keeps wear properties until it has been exhausted. Surface roughness is another important parameters for the friction materials, since rough surface containing deep groves must be kept from the beginning of the friction to the end of the friction. The continuous rough surface can only be provided with powder metallurgical composite parts. The friction materials must have hard and soft grains, and between these grains solid lubricant and porosity should be present. This combination can give the desired coefficient of friction and the continued surface roughness.
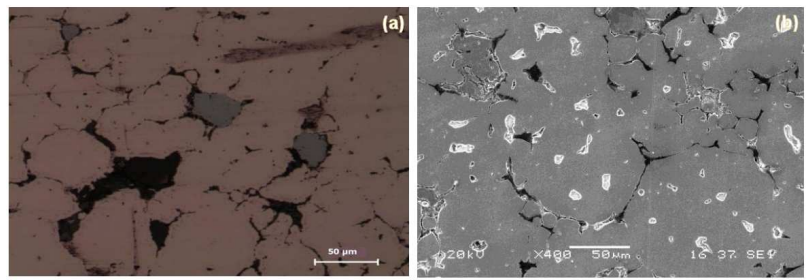

Fig. 1. Optical (a) and SEM (b) images of the sintered bronze samples.

Different amounts of graphite powders (1-8 wt.\%) were added to the CuSn10 alloy powder as solid lubricant before compaction and sintering. During wearing, graphite addition has dropped the coefficient of friction as shown in Fig. 2. Especially the coefficient of friction has drop sharply from 0.53 to 0.17 in sample with 2 wt.\% of graphite. In the SEM image shown in Fig. 3, it can be seen that the worn surface is covered with scales; there is evident interface between the matrix and the scales. It has been mentioned that grooves or pits generate during wear processes accompanied with wear debris. Part of debris break away from the worn surface, while the rest accumulate in grooves or pits and transform into friction film under the action of multiaxial stress. As a result of friction, the intergranular graphite becomes part of the surface film, acts a solid lubrication and decreases the coefficient of friction, as shown in Fig. 2.

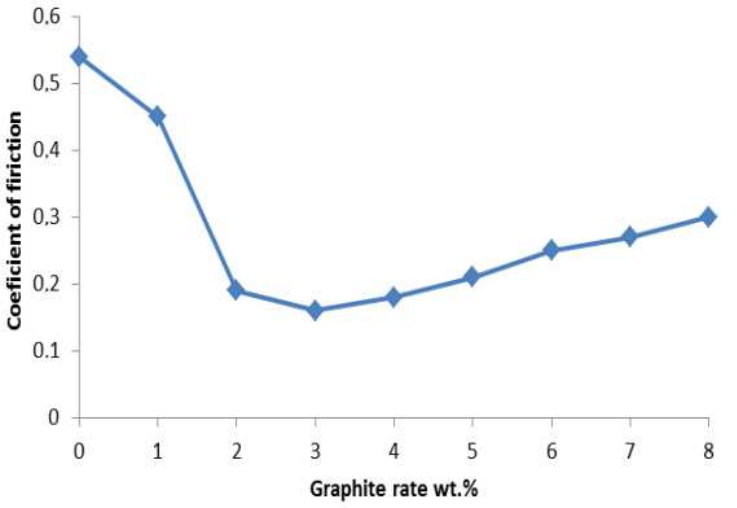

Fig. 2. Coefficient of friction versus graphite content.

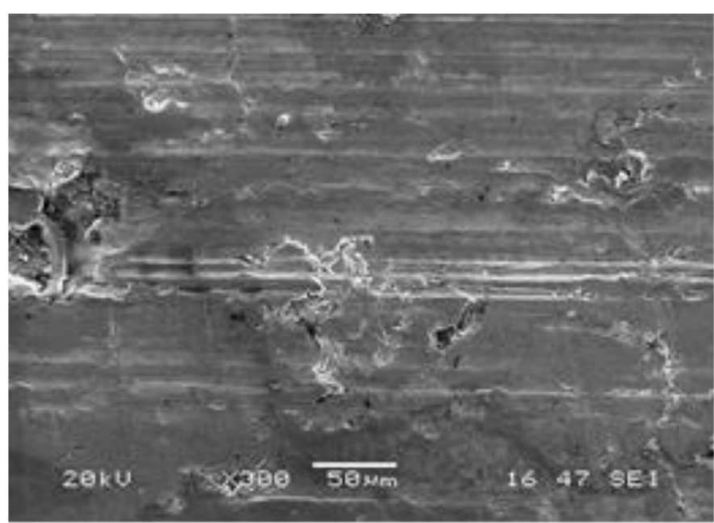

Fig. 3. Friction surfaces of sintered bronze pad.

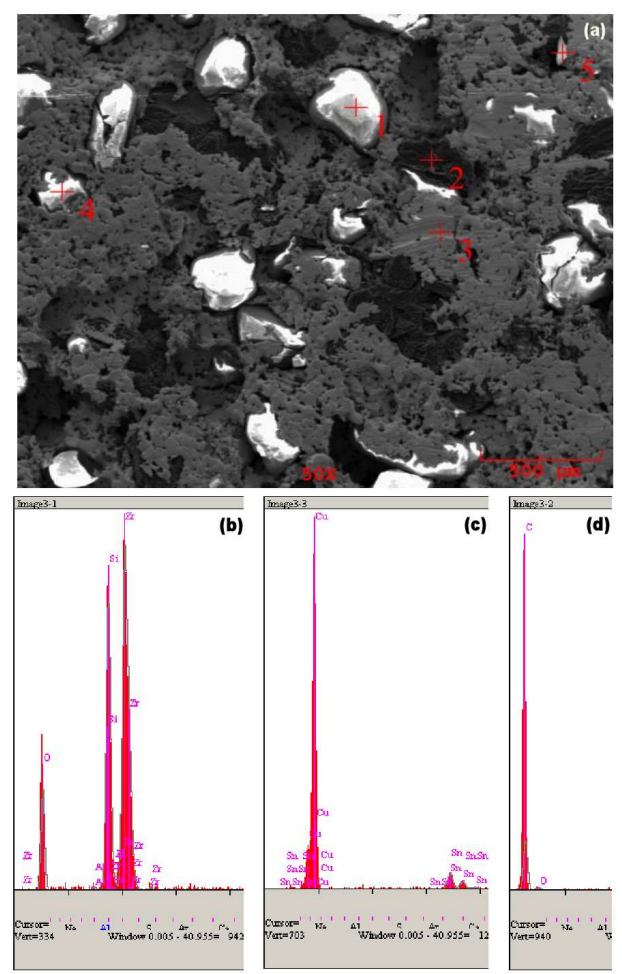

Fig. 4. EDS analysis of the bronze pad (a) SEM image of the pad surface, (b) particle addition, (c) bronze matrix, (d) graphite addition. 
A commercial bronze pad was also examined in the SEM and a number of EDS analyses were performed, as shown in Fig. 4. The SEM image has revealed that hard particles were present as well as particles of $\mathrm{Cu}-\mathrm{Sn}$ alloy and chunks of graphite, as illustrated in Fig. 4a. In Fig. 4b, EDS results show that zirconium, silicon and oxygen elements were detected in the white hard particles. Therefore, these particle are most probably zirconium silicate $\left(\mathrm{ZrSiO}_{4}\right)$ which was added as a reinforcement. This ceramic additive increases the pad span, changing wear behaviour such as coefficient of friction, wear rate and surface cracking. Other EDS results prove that $\mathrm{Cu}-\mathrm{Sn}$ alloy and rough graphite particles are present within the pad, which resembles our home-made bronze samples. So when both pads compared, the only difference is that the commercial one contains oxide particles which increase the wear rate. In terms of coefficient of friction, no significant differences have been observed.

\section{Conclusions}

Densification of green bodies in an atmospherecontrolled furnace was accomplished and graphitecontaining PM CuSn10 bronze pads were produced. By changing the graphite addition, it is possible to control friction force and therefore the coefficient of friction. Wear tests have revealed that constant surface friction properties can be obtained until wearing ends, and that these produced bronze pads can be used as clutch linings. An oxide-particle-reinforced, graphite-containing bronze matrix composite commercial pads were also examined. Both matrices show approximately the same wear behaviour. However, since commercial clutch lining contains oxide particles, its life-span is increased compared with the home-made bronze pads.

\section{References}

[1] W. Ma, J. Lu, B. Wang, Wear 266, 1072 (2009).

[2] R. Junghans, J. Neukirchner, D. Schumann, K.H. Lippman, Tribol. Int. 29, 181 (1996).

[3] S.F. Moustafa, S.A. El-Badry, A.M. Sanad, B. Kieback, Wear 253, 699 (2002).

[4] J. Jun-Hong, C. Jian-Min, Z. Hui-Di, W. Jing-Bo, Z. Hua, Tribol. Int. 37, 423 (2004).

[5] C.G. Clarke, C. Allen. Tribol. Int. 24, 109 (1991).

[6] S.F Moustafa S.A. El-Badry, A.M. Sanad, Powder Metall. 40, 201 (1997). 